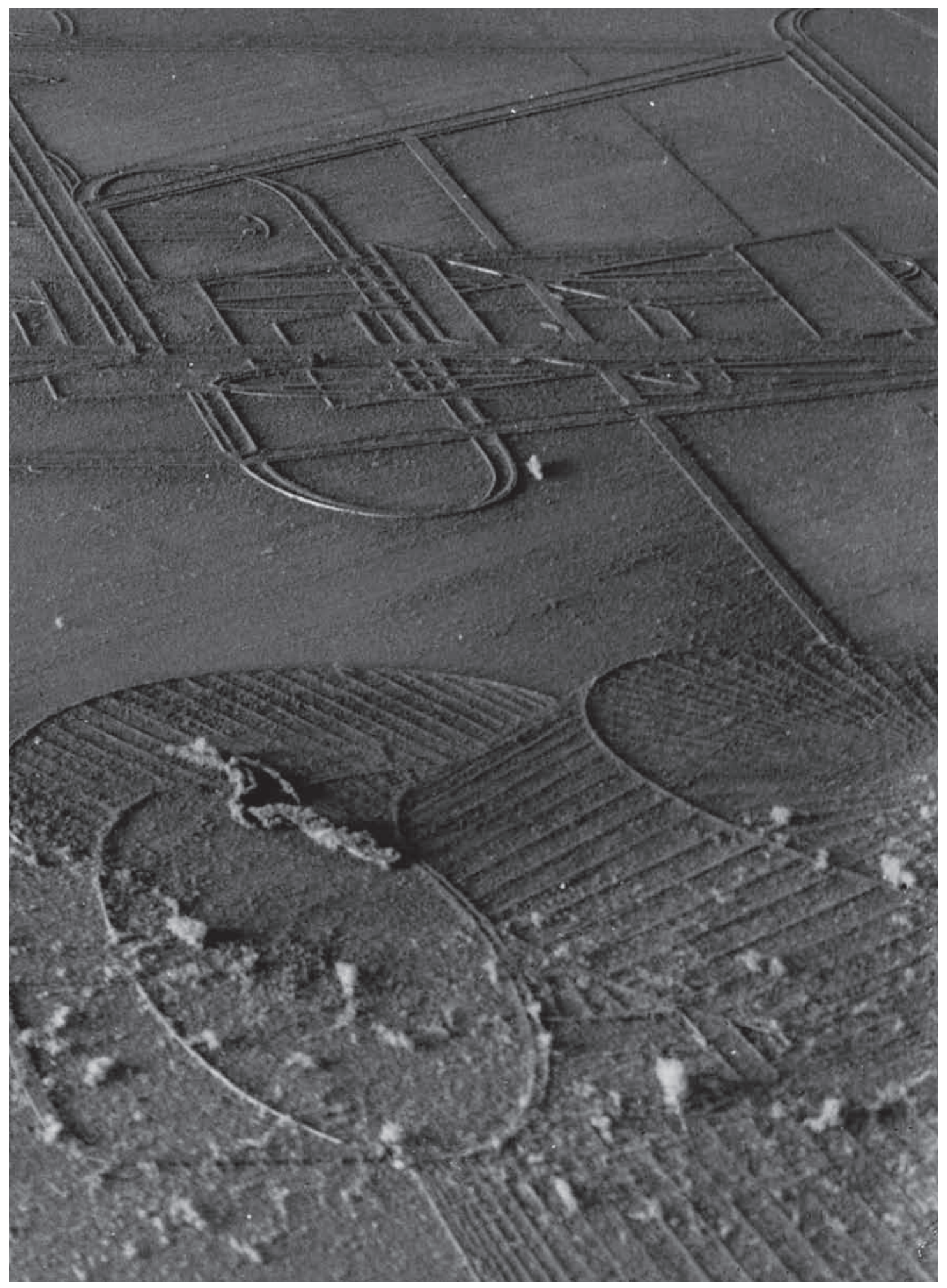


ARS Gabriel Menotti*

ano 11

n. 22

\section{Obras à mostra: articulações do trabalho de arte pelo desenho de exposição.}

Works on Display: arrangements of the artwork by exhibition design.

palavras-chave: processos de criação, obras de arte, curadoria, desenho de exposição, ator-rede.

keywords: creative processes, artworks, curating, exhibition design, actor-network theory.
Man Ray, Dust Breeding, impressão fotográfica de 1920, [detalhe].

*Universidade Federal do Espírito Santo (UFES).
Esse artigo examina processos tradicionalmente envolvidos nas práticas curatoriais e a maneira pela qual estas se definiriam historicamente em contraposição ao gesto artístico. Serão delineadas as origens institucionais da curadoria, a renegociação do papel do curador durante o modernismo e algumas perspectivas contemporâneas sobre a curadoria independente. Nesse percurso, analisaremos como projetos de exposição realizados tanto por curadores quanto por artistas contribuem ativamente na produção de trabalhos artísticos e na consolidação de determinadas técnicas e linguagens. Por fim, procuraremos sustentar que as práticas curatoriais constituem uma forma de design, podendo ser mais bem compreendidas em termos de arranjos expositivos (exhibition designs).

This paper examines processes traditionally involved in curatorial practices and how they have been historically defined in contraposition to the artistic gesture. It will outline curatorship's institutional origin, the renegotiation of the curator's role during modernity, and some contemporary perspectives over independent curating. Throughout this course, it will analyze how exhibition projects made both by curators and artists have actively contributed to the production of artistic works and the consolidation of certain techniques and languages. Finally, it will propose that curatorial practices could be better understood in terms of exhibition designing. 
Este artigo busca avançar no projeto de criar bases para uma compreensão relacional do fazer artístico, mais atenta a todo o desenvolvimento midiático que se deu a partir do final do século XIX e à influência que esse desenvolvimento pode ter causado nos paradigmas estéticos da sociedade contemporânea. De acordo com essa perspectiva, a obra em exposição não seria uma simples representação da vontade do artista, nem sequer uma expressão direta de seu processo de criação, mas sim uma coi$s a$ disputada, em que diversas agências confluem e se deixam vislumbrar.

Aqui, a partir desse renovado entendimento, buscaremos promover outra abordagem sobre a exibição de arte, delineando com maior precisão os entrelaçamentos das práticas curatoriais com a obra, trazendo à tona a autonomia do curador e seu papel na comunicação do trabalho de arte e, finalmente, ressaltando efeitos particulares do desenho de exposições como um campo criativo.

Inicialmente, a intervenção curatorial parece meramente prover um contexto específico para o encontro com a obra, oscilando entre extremos que podem ser descritos como interpretação e experiência. Sir Nicholas Serota, diretor da galeria britânica Tate, coloca esse binômio como o grande "dilema dos museus de arte moderna" . Cada um desses enfoques representa uma maneira radicalmente distinta de enquadrar o trabalho artístico.

De um lado (interpretação), estaria o intento de abrir a obra à compreensão do público, dissecando as linhas de força detrás de sua fabricação. A exposição viria a localizar o trabalho em uma determinada narrativa histórica, técnica e/ou sociopolítica, promovendo uma leitura que explicitaria relações formais e temáticas que por vezes escapam aos próprios criadores. O museu assim planejado teria ares de enciclopédia, e como tal estaria repleto de notas de verbetes: etiquetas, diagramas e textos de parede. Sua mera organização espacial corresponderia a um modelo taxonômico, uma lógica interpretativa que a exposição buscaria promover.

Por outro lado (experiência), haveria o esforço de exibir a obra da maneira a mais desimpedida possível, de modo que nada viesse a intervir entre a percepção do público e a essência (ou a presença) do trabalho. Nesse sentido, o papel da curadoria seria o de estabelecer um ambiente alegadamente neutro e livre de distrações - um canal transparente em que a obra pudesse se mostrar por completo. De acordo com o vocabulário de Bruno Latour, poderíamos dizer que esse segundo paradigma ressaltaria o papel da exposição como uma intermediária passiva do fazer artístico, enquanto que o enfoque interpretativo indicaria a sua função mediadora. 
Serota chama a atenção para as condições históricas de cada uma dessas abordagens, a primeira das quais teria acompanhado a curadoria desde meados do século XIX, enquanto a segunda emergiria com o modernismo, por volta da década de 1930. Para ele, no entanto, ambas as perspectivas se mostrariam incapazes de dar conta das recentes mudanças na natureza da produção artística.

Nesse sentido, o curador propõe uma terceira via, baseada nos projetos de pequenos museus, que sofrem menor pressão institucional. Esse novo paradigma pode ser entendido como o da contaminação, em que a exposição estaria voltada a "promover diferentes modos e níveis de "interpretação' por meio da sutil justaposição de 'experiências””2.

Embora identifique esse "princípio dialético" principalmente na organização de coleções particulares, Serota tem percebido a sua crescente aplicação em museus e galerias públicas. Ele evoca por exemplo o Hallen für Neue Kunst (na cidade de Schaffhausen, na Suíça), cujos pisos abertos possibilitam a reunião de diversos trabalhos de arte em clusters que se justapõem e se fundem.

Em oposição a uma organização compartimentada em salas (que produziria rígidas separações entre períodos históricos, escolas de arte, autores, temáticas e formatos), Serota entende esses clusters como "zonas de influência” que abrem o conjunto de obras a leituras e comparações inesperadas.

Um caso mais explícito dessa abordagem estaria no projeto do diretor Jean-Christophe Ammann para o Museum für Moderne Kunst de Frankfurt, aberto em 1991. Ammann propõe a criação de semelhantes "zonas climáticas" entre as obras, que entretanto não dependeriam de qualquer configuração arquitetônica prévia. Nesse sentido, ele já teria convidado artistas para apresentar trabalhos nos "espaços de serviço" do museu, abrindo o próprio edifício ao jogo de interpretações pessoais produzido durante uma exposição.

De modo geral, o que esse "novo" paradigma advogado por Serota pretende é assumir plenamente o caráter intersubjetivo e processual $d a$ exposição, ao integrar diversas obras em uma "matriz de conexões variáveis a ser explorada pelos visitantes de acordo com seus interesses e sensibilidades particulares". Dessa forma, "curadores e visitantes teriam que se dispor a redesenhar o mapa da arte moderna, ao invés de seguir o caminho previsto por um curador"3.

Entretanto, aí também parece estar a principal limitação da ideia de "zonas de influência”. Embora resolva a falsa dicotomia entre experiência e 
interpretação, essa abordagem permanece impermeável ao caráter intersubjetivo e processual da arte em si, negligenciando a condição de disputa das obras em exposição. O fato é que não existem textos separados de contextos: tanto obras quanto exposições são redes que se interpenetram.

Como vimos anteriormente, os próprios trabalhos de arte devem ser tomados como "matrizes de conexão variável”. A "arte moderna” não seria nada além de uma acumulação de "mapas" que resultam da concorrência de diversos percursos físicos e conceituais. Logo, não seria possível dissociar a obra das várias "influências" que ela sofre, nem o fazer artístico da intervenção curatorial que o coloca em evidência.

De modo a considerar a interação das práticas curatoriais com o fazer artístico em toda a sua profundidade, acompanharemos a seguir a história dessas práticas. Nesse trajeto, examinaremos os paradigmas enumerados por Serota, buscando demonstrar como a obra em exposição é delimitada por contingências. Concluiremos propondo outra forma de entender o arranjo expositivo (exhibition design) com base nas ideias de Bruno Latour ${ }^{4}$.

\section{Interpretação ou institucionalização?}

A função de curador é tão velha quanto o antigo Império Romano, onde o título (que significa literalmente "tomador de conta") era "dado a oficiais encarregados de vários departamentos de serviços públicos: saneamento, transporte, polícia, etc. ${ }^{5}$. Sua acepção moderna, entretanto, é um produto do mercado de arte burguês ${ }^{6}$.

No entender de Cummings e Lewandowska ${ }^{7}$, o antecessor direto do curador contemporâneo é o especialista que, até o século XVIII, era o único capaz de aferir a autenticidade das obras negociadas por colecionadores particulares, sendo responsável por determinar o seu valor.

Esse personagem atuava como consultor da nobreza europeia na organização de seus Wunderkammers (os gabinetes de curiosidades): coleções que reuniam artefatos das mais diversas ordens, sem obedecer a nenhum "princípio ordenador comum" senão a raridade, e que tinham como principal função social simbolizar o poder e status de seu proprietário.

Já nessa época, o especialista possuía um papel central na economia simbólica rudimentar do mundo da arte, em que um número restrito de souvenires, relíquias, antiguidades e pinturas circulava entre uma quantidade ainda menor de colecionadores abastados.

\section{GABRIEL MENOTTI}

Obras à mostra: articulações do trabalho de arte pelo desenho de exposição.

4. Cf. LATOUR, Bruno. A cautious Prometheus? A few steps toward a philosophy of design (with special attention to Peter Sloterdijk). In: HACKNE, Fiona; GLYNNE, Jonath; MINTO, Viv (eds.). Annals of the Annual International Conference of the Design History Society. London: Universal Publishers, 2008, p. 2-10.

5. Cf. STRAUSS, David Levi. The bias of the world: curating after Szeemann e Hopps. In: RAND, Steven, e KOURIS, Heather (eds.). Cautionary tales: critical curating. Nova York: Apexart, 2007, p. 15-25.

6. Cf. CARRIER, David. Why Curators Matter. In: ibidem, p. 79-90.

7. CUMMINGS, Neil e LEWANDOWSKA, Marysia. The value of things. Basel: Birkhäuser, 2000, p. 36. 
No final do século XVIII, com a emergência de jovens repúblicas, grande parte dessas coleções particulares foi transferida para o domínio

n. 22 do Estado, dando origem aos primeiros museus públicos. O pioneiro deles foi o Museu Britânico, aberto em 1759 em Londres. O acervo inaugural dessa instituição proveio do espólio do médico sir Hans Sloane: um total de 79.575 artefatos, cedidos à nação pelo rei George II.

O simultâneo apogeu do programa intelectual iluminista vai induzir uma transformação significativa no propósito dessas coleções. A acumulação de artefatos deixa de ser um "mero" sinal de prestígio (agora, do Estado), passando a constituir também um repositório que afiança a sociedade

8. Ibidem, p. 31.

9. Ibidem.

10. Ibidem, p. 29.

Figura 2

Ilustração representando

o gabinete de

curiosidades do antiquário Ole Worm.

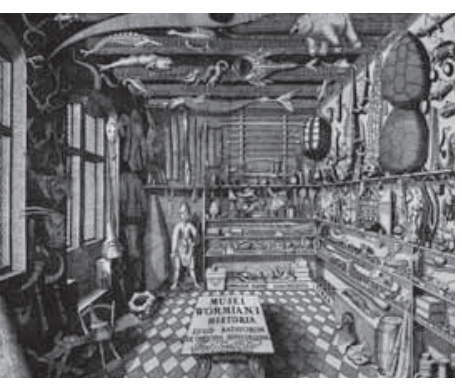
contra a "inevitabilidade da perda, do esquecimento e da incompletude" .

Assim, o museu surge como uma instituição quase enciclopédica, guiada por princípios de ordem - entendida como "a habilidade de recuperar e interpretar" ". É nesse "departamento de serviços públicos" que os antigos consultores da nobreza vão se alojar, assumindo o papel de curadores. Sua expertise será a partir de então aplicada na tarefa de classificar artefatos, definindo quais merecem ser privilegiados em meio ao amontoado de informações, devendo ser conservados e exibidos.

Nessa "recém-inventada" função de curador, a capacidade de aferir valor material se mistura perigosamente ao poder de administrar o conhecimento simbólico da humanidade. Antes de prosseguirmos com o exame das consequências desse fato para o fazer artístico, é preciso ressaltar duas características fundamentais do pioneiro Museu Britânico.

A primeira é que, apesar de sua dimensão pública, a instituição ainda estava restrita à aristocracia. Embora o acesso ao Museu Britânico fosse gratuito, era necessário preencher um cadastro por escrito e obedecer a rígidas regras de etiqueta para poder frequentá-lo. Além disso, todas as visitas eram guiadas, de forma a "regular o fluxo de pessoas pelo prédio", assegurando a atmosfera "correta" para apreciação do acervo ${ }^{10}$.

A segunda é que a instituição constituía um centro de referência acadêmica, não sendo originalmente voltada à apreciação estética. As primeiras coleções do Museu Britânico (uma biblioteca, um departamento de história natural e outro de arqueologia) estavam em exibição para fins de estudo. Nesse sentido, as galerias do museu podem ser consideradas dispositivos de análise, onde nenhum artefato existia para ser simplesmente admirado.

É de acordo com esses princípios sistematizantes que os primeiros curadores vão se aproximar do trabalho artístico. Em verdade, as obras 
"de arte" ganham espaço no museu não por causa de seu valor estético GABRIEL MENOTTI intrínseco, mas seguindo um lastro acadêmico, condicionado pela emergente disciplina de História da Arte ${ }^{11}$. O curador Christian von Mechel, responsável por administrar a coleção de arte real vienense, teria declarado em 1778 que o propósito do museu era tornar essa História visível. Doravante, a exposição da obra de arte deveria encarnar os postulados metodológicos dessa disciplina ${ }^{12}$.

Essa abordagem historiográfica viria a se confirmar no Museu do Louvre, em Paris, considerado o primeiro museu "no sentido moderno". O Louvre era um palácio que abrigava uma vasta coleção de arte da monarquia francesa quando, em 1792, a revolução vai abri-lo ao público, com base no princípio de que todos os cidadãos deveriam ter acesso à "propriedade privada com valor cultural"13.

O primeiro diretor do museu foi Dominique Vivant, barão de Denon, um diplomata e arqueólogo indicado diretamente por Napoleão. Seguindo o projeto burguês de "suplantar interpretações religiosas ou ideológicas com leituras puramente estéticas ou históricas”"14, Vivant irá propor que a instalação das obras seja baseada em predicados aparentemente neutros como "cronologia, evolução artística e nacionalidade"15.

Em 1887, na Galeria Nacional britânica, esse princípio organizacional será complementado com um formato também neutro de instalação: o alinhamento dos quadros no nível do olhar, em conjuntos esteticamente equilibrados. Dessa maneira, estariam consolidadas aquelas que seriam "as convenções de exibição na maior parte das galerias públicas [ocidentais] até a década de 1980"16.

Entretanto, por trás dessa aparente "imparcialidade acadêmica", existia, sim, um forte desígnio político na exposição de arte. Não havia nada de "puramente estético" no Museu do Louvre, por exemplo. Não podemos esquecer que essa instituição surgiu como um "símbolo das conquistas revolucionárias" 17 , destinado a desempenhar um papel central na "formação e desenvolvimento de uma nova sociedade"18.

Nesse sentido, mais do que simplesmente analisar o trabalho artístico, a abordagem interpretativa buscava mobilizar as obras de arte de modo a satisfazer as "necessidades culturais da emergente classe burguesa"19. Isso implicava a construção de narrativas que suportassem valores hegemônicos e promovessem determinadas representações de nação, história e sociedade.

Obras à mostra: articulações do trabalho de arte pelo desenho de exposição.

11. Cf. CUMMINGS, Neil e LEWANDOWSKA, Marysia. Op. cit., p. 33.

12. Cf. ibidem.

13. SCHUBERT, Karsten. Op. cit., p. 18.

14. Ibidem, p. 19.

15. Ibidem, p. 22.

16. SEROTA, Nicholas. Op. cit., p. 7.

17. SCHUBERT, Karsten. Op. cit., p. 18.

18. Ibidem, p. 19.

19. Ibidem, p. 22.

Figura 3 sala Elgin do Museu Britânico (1937).

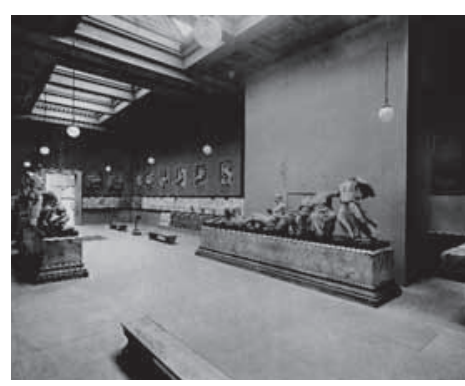


Em outras palavras, a exposição já estaria operando como o que Nicolas Bourriaud viria a descrever como uma "unidade de base a partir

20. BOURRIAUD, Nicolas. Estética relacional. Buenos Aires: Adriana Hidalgo Editora, 2006, p. 88.

21. CUMMINGS, Neil e LEWANDOWSKA, Marysia. Op. cit., p. 41.

22. Cf. CARRIER, David. In: RAND, Steven e KOURIS, Heather (eds.). Op. cit., p. 80-81.

23. Cf. GROYS, Boris. The curator as iconoclast. In: RAND, Steven e KOURIS, Heather (eds.). Op. cit., p. 46.

24. Cf. ibidem, p. 47. da qual seria possível pensar as relações entre a arte e a ideologia induzida pelas técnicas, em detrimento da obra individual"20. Por "pensar", devemos entender não somente "refletir", mas também "racionalizar e propor". Isso quer dizer que o museu estaria apto a negociar nossa relação com o "presente materialmente confuso" por meio da fabricação de um "passado contínuo e estável”21.

Particularmente relevante para esse trabalho é a forma como as obras são articuladas no museu de modo a consolidar a própria história da arte em que elas estariam inseridas. Devido às suas condições excepcionais de publicidade, a exposição constitui o principal canal para revelar a produção artística e consolidar a sua reputação, de modo que o trabalho do curador acaba por prevalecer sobre a pesquisa acadêmica ${ }^{22}$. Dessa maneira, a exposição não estaria dando a ver narrativas transcendentais sobre o fazer artístico, mas essencialmente fabricando essas narrativas.

Ao criar uma história "da arte", as práticas curatoriais também criariam condições para a existência "artística" da obra. Referindo-se a esses primeiros museus, Boris Groys teria declarado que quem detinha o poder de produzir arte não era um "artista", mas sim o curador - que, com seu gesto iconoclasta, "desfuncionalizava” artefatos rituais e símbolos de poder e riqueza, transformando-os em objetos de pura contemplação ${ }^{23}$.

Em resumo, podemos dizer que o enfoque interpretativo dos primeiros museus promoverá uma mediação do fazer artístico que acabará por definir o seu lugar na sociedade burguesa do século XIX. Nesse processo, entretanto, a obra se encontrava reduzida a um mero intermediário de narrativas institucionais e valores estéticos hegemônicos - quaisquer que eles fossem.

\section{A esquizofrênica assepsia do cubo branco}

Se levarmos em consideração os argumentos de Groys, a mudança no paradigma das práticas curatoriais (de interpretação da obra para a promoção de sua experiência) aparece como uma conquista dos próprios artistas. Percebendo que o museu estaria se tornando o novo "lugar de culto" da civilização ocidental, esses personagens passariam a atuar tendo esse espaço como o seu foco primário ${ }^{24}$. 
Logo, o artista assumiria o poder sobre a criação da obra ao comeGABRIEL MENOTTI çar a desenvolver uma produção que entraria em diálogo explícito com a fabricação histórica das instituições de arte, simultaneamente desarmando curadores e emancipando o fazer artístico. O símbolo maior dessa mudança estaria, obviamente, em Marcel Duchamp e seu urinol ${ }^{25}$.

Mas, assim como a autonomia da Fonte pode ser questionada, também é possível interrogar a consagração da galeria de arte como um espaço de culto contemporâneo. Prestando mais atenção, iremos perceber que a transformação do caráter desse espaço de uma "iconoclastia iluminista" para uma "iconofilia romântica" ${ }^{26}$ corresponde a uma profunda reorganização geopolítica.

Segundo Karsten Schubert ${ }^{27}$, com o fim do novo imperialismo europeu no início do século $\mathrm{XX}$, o projeto museológico que estava em curso perdeu o seu rumo: não havia mais espólios coloniais a acumular nem a necessidade de demarcar a identidade de jovens nações. Gradualmente, o escopo acadêmico do museu vai se diluir, cedendo lugar a um programa estético-pedagógico acessível a uma audiência mais ampla (e até internacional).

Os primeiros marcos do novo modelo surgem em Berlim. São instituições como o Kaiser-Friedrich-Museum (inaugurado em 1897, posteriormente rebatizado de Bodemuseum, em homenagem ao seu criador, Wilhem Bode) e o Pergamon (de 1930). Nesses espaços, inicia-se um esforço para superar a abordagem puramente taxonômica da exposição de arte. $\mathrm{O}$ curador passa a levar em consideração aspectos estéticos não apenas das obras, mas também da forma de apresentá-las.

Essa preocupação estética vai se traduzir em um ambiente espartano, marcado por "simplicidade e arejamento", que pode ser perfeitamente exemplificado pela arquitetura de interior do Pergamon:

Não havia nenhum traço de ornamentos ou decoração adicionais. As paredes eram pálidas, a iluminação era funcional, os pedestais eram minimalistas. As antiguidades não estavam lá para ilustrar uma cronologia, mas como trabalhos de arte em si mesmas ${ }^{28}$.

A grande revolução museológica, entretanto, acabará por se dar do outro lado do oceano, mais precisamente na cidade de Nova York. É com o seu Museu de Arte Moderna (Museum of Modern Art - MoMA), inaugurado em 1929, que um novo paradigma expositivo vai definitivamente se instaurar. 
O MoMA já surgiu divorciado das principais tradições que regiam as instituições europeias. Tratava-se do primeiro museu dedicado exclusivamente à arte moderna, comprometido não apenas em documentar e exibir essa produção, mas também em fomentá-la -desde então participando ativamente da cena artística internacional.

De maneira semelhante, ele se propunha a romper com as convenções arquitetônicas dos museus da sua época, a começar pelo lado de fora. Ao invés de estar instalado em um edifício monumental, o MoMA inicialmente ocupou galerias no $12^{\circ}$ andar de um prédio de escritórios localizado na Quinta Avenida. E uma transformação ainda mais radical viria a acontecer no seu interior, com a consolidação do modelo expositivo que posteriormente viria a ser batizado de cubo branco.

"Cubo branco", na definição do artista Brian O’Doherty, se refere a uma configuração do espaço que pretende "subtrai[r] da obra de arte todos os indícios que interfiram no fato de que ela é 'arte”". Isso implica isolar a obra "de tudo que possa prejudicar sua apreciação de si mesma" por meio de uma rigorosa neutralização do ambiente da galeria:

29. O'DOHERTY, Brian. No interior do cubo branco: a ideologia do espaço da arte. São Paulo: Brasiliense, 2002, p. 4.

30. Ibidem, p. 4.

31. Ibidem, p. XVI.
O mundo exterior não deve entrar, de modo que as janelas geralmente são lacradas. As paredes são pintadas de branco. O teto torna-se fonte de luz. O chão de madeira é polido, para que você provoque estalidos austeros ao andar, ou acarpetado, para que você ande sem ruído. A arte é livre, como se dizia, "para assumir vida própria"29.

Não obstante, essa "vida própria" da arte parece emergir às custas da aniquilação de todo o resto. O território asséptico do cubo branco "sublima as nuanças arquitetônicas do edifício”, produzindo uma homogeneização artificial na qual a própria presença do público "parece supérflua, uma intromissão" ${ }^{30}$. Nesse sentido, o espaço que corresponderia ao regime de experiência estética identificado por Serota parece querer se desmaterializar por completo.

Segundo o artista Brian O'Doherty, tal desmaterialização refletiria uma ideologia capitalista, apontando não para a real emancipação do fazer artístico, mas sim para a sua definitiva "comodificação". A galeria modernista ("um local para vender coisas") representaria um "limbo entre o ateliê e a sala de estar" em que o movimento criador "ajusta-se com perfeição ao desejo de posse burguês". Mesmo a "aparência extemporânea" produzida pelo cubo branco serviria primeiramente para indicar que "a obra já pertence à posteridade", se tratando, portanto, de "um bom investimento"31. 
Nesses termos, a promoção da experiência estética não parece se opor a uma abordagem curatorial acadêmico-interpretativa. Pelo contrário, o cubo branco vem a coroar as pretensões de neutralidade (do espaço expositivo) e autonomia (da obra) que se insinuavam nas primeiras instituições de arte.

Sob o regime curatorial que Groys chamou de iconoclasta, a exposição distanciava a obra da sua rede de criação, de modo a mobilizá-la como elemento intermediário de uma determinada consciência histórica ou programa de pensamento. Sobre o pedestal modernista, entretanto, a obra se encontra ainda mais alienada da realidade. Mesmo a forma de apreciá-la está prescrita na configuração do espaço. A arte passa a existir de maneira esotérica, em um futuro impossível - o que quer dizer: em lugar nenhum. Essa posição parece lhe conferir valor e sentido absolutos, à revelia dos diversos processos intersubjetivos que continuam por atravessá-la. Em outras palavras, a obra deixa de ser uma coisa disputada e passa a ser um objeto acabado.

Como procuramos demonstrar em outro artigo $^{32}$, um tal fechamento não é próprio do processo criativo - e nem sequer da obra, por maiores que sejam os privilégios dados a esse vestígio do movimento criador. Se a obra em exposição parece um objeto singular e harmonioso, chegando a dar impressão de transcender a matéria, é sobretudo por causa de suas dinâmicas de exposição - ou seja: da intervenção do curador.

Todavia, o principal efeito da assepsia do cubo branco na organização do fazer artístico parece consistir não em sobredeterminar o valor $e$ sentido da obra, mas sim em esconder o fato de que o próprio território de exposição está em constante disputa. Nesse sentido, mais do que produzir a sensação de totalidade do trabalho de arte, essa configuração do espaço estaria reforçando a alegada neutralidade da galeria.

\section{Abrindo o espaço da galeria ao conflito}

A história oficial dos paradigmas de exposição sugere ciclos de ação e reação. Serota aponta que os próprios artistas, tomando consciência das convenções de neutralidade que se estabelecem, passarão a se relacionar criticamente com o espaço da galeria, incitando outras abordagens curatoriais ${ }^{33}$.

Na leitura de O’Doherty, essa superação do cubo branco parece uma fatalidade ainda mais inevitável. Diz ele que, "à medida em que o modernismo envelhece, o contexto torna-se conteúdo" ${ }^{34}$. Em outras palavras, ao invés de meramente produzir para a exposição, como colocado por 
ARS Groys, o artista passará a produzir nela ou com ela-deslocando, assim, "o ano 11 seu lugar de trabalho da reclusão do estúdio privado para a arena pública n. 22 do museu”35. Um exemplo dessa tendência seria o trabalho 8 Cuts (1967), de Carl Andre: uma trabalho que consistiu na remoção de tijolos do piso da galeria, "criando vazios no volume da sala" ${ }^{36}$.

É a qualidade de bricolagem da produção pós-moderna que vai, finalmente, entrelaçar a "superfície pictórica" da obra às paredes da galeria, fundindo-as em uma única "unidade de discurso" ${ }^{37}$. Gêneros como

35. SEROTA, Nicholas. Op. cit., p. 20.

36. Ibidem, p. 33.

37. O'DOHERTY, Brian. Op. cit., p. 36.

38. Ibidem, p. 89.

39. STANISZEWSKI, Mary Anne. The power of display: a history of exhibition installations at the Museum of Modern Art. Cambridge: MIT Press, 1998, p. XXII.

40. Ibidem, p. 27. a instalação e o site specific vão assumir uma singularidade nitidamente provisória, subordinada ao espaço de exposição. Atento para esse fato, O’Doherty conclui que, com o pós-modernismo, o recinto da galeria já não é mais neutro, se tornando "uma membrana através da qual os valores estéticos e os comercias permutam-se por osmose" ${ }^{38}$.

O que escapa a essa interpretação é que mesmo o trabalho de arte mais autocontido constitui-se como uma assemblage de forças e atores diversos. Igualmente, segundo a linha de raciocínio desenvolvida até aqui, o espaço expositivo nunca chegou a ser neutro- e basta retornarmos o olhar para a Europa de 1920 para percebermos que a assepsia museográfica do MoMA já nasceria superada.

O trabalho então desenvolvido por vanguardas como os surrealistas, o movimento holandês De Stijle a escola alemã Bauhaus (de Weimar) não estava pautado apenas pela produção de artefatos, mas também pela definição de maneiras de exibi-los. Logo, esses grupos vão se embrenhar por aquilo que Mary Anne Staniszewski chamou de o "inconsciente" das exposições de arte: o desenho de instalações ${ }^{39}$.

É na tarefa aparentemente prosaica de dispor elementos no espaço que se manifestam mais claramente as "limitações históricas e códigos sociais” da exposição. Nesse sentido, o empreendimento das vanguardas se comprometia a divisar métodos que possibilitassem "rejeitar o idealismo estético e a autonomia cultural e tratar a exposição como uma experiência historicamente determinada, cujo significado é talhado pela sua recepção" ${ }^{40}$.

Dado o escopo desta pesquisa, é conveniente ressaltar que essa inclinação curatorial não decorria de uma simples reação dialética ao establishment da galeria de arte moderna. Staniszewski indica que as vanguardas estariam motivadas por fenômenos como inovações tecnológicas, mídias de massa e interatividade. Assim, elas se apropriariam do desenho de instalações como "uma nova fronteira entre arte e comunicação de massa”, ressaltando os aspectos midiáticos da exposição. 
Não é difícil perceber como a ideia de uma rede intersubjetiva e inacabada já se encontra rascunhada na noção de "ambiente total" cunhada por De Stijl, que concebia as exposições e seus elementos como "experiências dinâmicas para uma audiência que se movia através das instalações e interagia com elas" ${ }^{41}$.

Um dos primeiros terrenos para esse tipo de experimentação foi o Museu Estadual (Landesmuseum) de Hannover, na Alemanha. Ao assumir a diretoria da instituição em 1925, após passar dois anos como seu curador, o historiador da arte Alexander Dorner planejava reestruturá-la. Sua principal estratégia nesse sentido consistia na criação de “'salas atmosféricas' que evocassem o espírito de um determinado período e imergissem o espectador em uma cultura específica" ${ }^{42}$. Desse modo, o contexto histórico passava a ser francamente "performado" pela arquitetura de exposição. Por exemplo:

As galerias da Renascença foram pintadas de branco ou cinza de modo a enfatizar o caráter cúbico das salas e o interesse do período no espaço geométrico e na perspectiva. Nas galerias do Barroco, as paredes eram cobertas por veludo vermelho e as pinturas estavam contidas em molduras douradas ${ }^{43}$.

Dorner também vai abrir espaço para a intervenção de artistas no projeto museográfico da instituição, trazendo à tona a co-operação entre o fazer artístico e as práticas curatoriais que é racionalizada pelos primeiros museus e sublimada no cubo branco.

Em 1926, ele convidaria o fotógrafo e designer El Lissitzky, pupilo de Malevich, para instalar no Landesmuseum uma versão da Sala para Arte Construtivista (Raum für konstruktive Kunst) que havia sido concebida para a Exposição de Arte Internacional em Dresden no mesmo ano. Esse momento é destacado na autobiografia de El Lissitzky de uma maneira que nos leva a questionar a divisão convencional de tarefas envolvidas na exibição de arte: "1926: meu trabalho mais importante como artista se inicia: a criação de exposições" ${ }^{4}$.

A parceria se desenvolveria nos anos seguintes (1927-28), dando forma àquele que é até hoje o trabalho mais conhecido de El Lissitzky: o Gabinete Abstrato (Abstraktes Kabinett). A intenção do artista com esse projeto foi criar um ambiente que pudesse "tornar o público ativo" no processo de apreciar a exposição.

Um dos elementos utilizados no Gabinete foram paredes cuja superfície trocava de cor (entre diversas nuances de branco, cinza e preto)

\section{GABRIEL MENOTTI}

Obras à mostra: articulações do trabalho de arte pelo desenho de exposição.

41. Ibidem, p. 14.

42. Ibidem, p. 16.

44. Ibidem, p. 21.

\section{Figura 5}

Instalação de 8 Cuts na Galeria Dwan, em Los Angeles (1967).

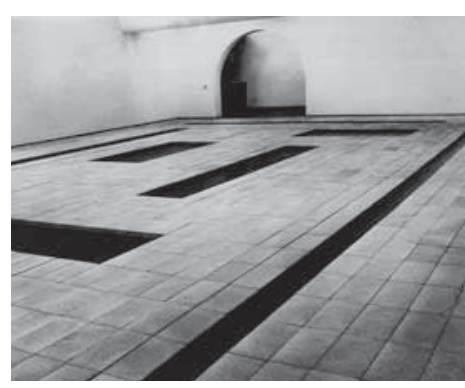


ARS devido à reflexão luminosa, conforme os visitantes se moviam pela galeria. ano 11 Outro, painéis deslizantes que expunham certas pinturas enquanto esconn. 22 diam outras, obrigando os visitantes a manipulá-los de modo a compreender todo o conjunto em exposição. El Lissitzky também quis implantar um sistema de luz automático, capaz de transformar a iluminação da sala, mas não havia infraestrutura disponível para isso no edifício.

É preciso ressaltar que o Gabinete Abstrato foi concebido como uma galeria permanente do Landesmuseum. Se tratava do espaço onde se encontravam à mostra os exemplares desse gênero de arte que faziam parte do seu acervo - representando, à época, o desfecho do percurso histórico em exposição.

A partir de 1930, outra galeria viria a dar sequência àquela de El Lissitzky na cronologia proposta pelo Landesmuseum - um espaço que comportasse tudo aquilo que então constituía "os mais recentes desenvolvimentos na cultura visual" ${ }^{45}$. A figura comissionada para desenhar essa Sala do Nosso Tempo (Raum der Gegenwart) foi outro artista: o pintor László Moholy-Nagy, professor da Bauhaus.

Com esse projeto, a crescente influência midiática na circulação da arte se torna ainda mais evidente. Staniszewski destaca que na Sala do Nosso Tempo não havia nenhuma obra original além de uma Máquina de Luz do próprio Moholy-Nagy ("que projetava padrões abstratos ao 46. Ibidem. toque de um botão") ${ }^{46}$. Tudo o que estava exposto eram documentos, reproduções e modelos; fotografias e textos que demonstravam inovações do desenho industrial e da arquitetura moderna; projetores com slides de apresentações de dança e montagens cenográficas.

Mais uma vez, a infraestrutura do museu não se mostrou preparada para suportar toda a extensão do projeto curatorial. Quando a galeria teve que ser inaugurada, parte dos dispositivos eletromecânicos ainda não estava funcionando adequadamente. Talvez seja significativo que, mesmo assim, a Sala do Nosso Tempo tenha sido aberta ao público, todavia em estado de franco inacabamento.

Como se pode notar nos desenhos de exposição organizados sob os auspícios de Dorner, as práticas curatoriais chegam a intervir materialmente na apresentação da obra de arte, sendo, portanto, capazes de ressaltar diferentes elementos de uma rede de criação que não o próprio artefato que dela (assumidamente) resulta. No Landesmuseum, essa intermediação estava voltada a comunicar mais detalhadamente certos aspectos do fazer artístico, relativos por exemplo às suas condições históricas de produção e recepção. 
Também sabemos, por outro lado, que a curadoria pode atuar em prol do ocultamento desses vários aspectos - como faz no caso do cubo branco. Agora, para entendermos até onde pode ir essa capacidade de mediação, precisamos nos perguntar: seria o desenho de instalação capaz de suprimir as próprias obras em exposição?

Aqui, é novamente Marcel Duchamp que aparece para revelar a complexidade das relações entre as práticas curatoriais e o fazer artístico. Duchamp se envolveu com o desenho de instalações ao ser convidado pelos surrealistas para planejar a apresentação de duas grandes mostras do movimento: a Exposição Surrealista Internacional de 1937 (em Paris) e a retrospectiva Primeiros Papéis do Surrealismo de 1942 (First Papers of Surrealism, em Nova York).Em ambos os casos, ele se apropriou do conjunto da exposição como um "terreno fértil para a sua criatividade" 47 , propondo formas de ocupação do espaço que rivalizavam diretamente com o acesso às obras.

Para a Exposição Internacional, ocorrida na Galeria de Belas Artes de Paris, Duchamp implementou o projeto Twelve Hundred Coal Bags Suspended from the Ceiling over a Stove. Como o nome indica, o principal elemento desse arranjo eram 1.200 sacos de carvão pendurados pelo teto da galeria. $\mathrm{O}$ chão foi todo coberto por folhas secas e ervas aromáticas, e o espaço era iluminado por apenas uma única lâmpada, instalada em um braseiro apagado. Além disso, lanternas foram distribuídas entre os visitantes, de modo que eles pudessem ver as obras em exposição ${ }^{48}$.

Já o projeto da retrospectiva foi chamado Sixteen Miles of String. Para esse, foi urdida uma enorme teia de barbante no espaço da galeria, emaranhando chão, teto e paredes. Além de atrapalhar a locomoção do público, esse artifício também impedia a visão de alguns trabalhos. De modo a criar outra camada de obstáculos, Duchamp combinou com o filho de um amigo que trouxesse seus coleguinhas para a inauguração da mostra. Dessa forma, a noite de abertura contou com uma dúzia de crianças correndo e jogando futebol entre as obras ${ }^{49}$.

Projetos de instalação como os de Duchamp subvertem a Gestalt convencional de uma galeria de arte, se interpondo às obras presentes e transformando-as em aspectos secundários da exposição - nas palavras de O'Doherty, um quase irrelevante "papel de parede" "50. Nesse sentido, o que esses projetos nos revelam é que a separação entre o conjunto de obras (como figura) e seu contexto de exposição (como fundo) é uma fabricação arbitrária, em parte sustentada (e, portanto, passível de ser destituída) pela intervenção curatorial.

47. Ibidem, p. 23.

48. Cf. STORRIE, Callum. The delirious museum: a journey from the Louvre to Las Vegas. Nova York: Tauris e Co, 2006, p. 53.

49. Cf. ibidem, p. 57.

50. O'DOHERTY, Brian. Op. cit., p. 79.

Figura 6

Reconstrução do Gabinete Abstrato no Halle für Kunst Lüneburg (2009).

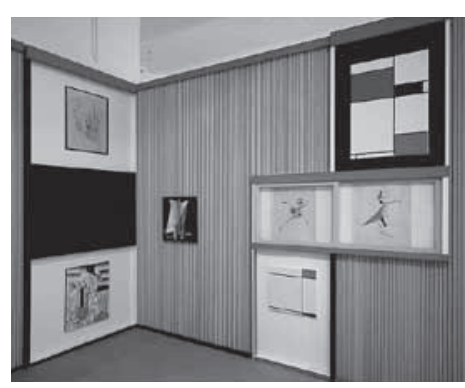


51. STANISZEWSKI, Mary Anne. Op. cit., p. 3.

52. Ibidem, p. 307.

53. MARTIN, JeanHubert. Independent curatorship. In: RAND,

Steven, e KOURIS, Heather (eds.). Op. cit., p. 43.

Figura 7 Reconstrução da Sala do Nosso Tempo no Van Abbemuseum (2010).
A longo prazo, os projetos expositivos das vanguardas não parecem ter promovido nenhuma consciência mais profunda sobre a função do curador na constituição da obra de arte. Ainda hoje, esses projetos não costumam ser entendidos como parte integrante da genealogia das práticas curatoriais, e sim como precursores daquele que é "um dos gêneros artísticos dominantes da cultura visual contemporânea": a instalação ${ }^{51}$.

Nesse sentido, devemos ressaltar o que Staniszewski considera o grande paradoxo do "dispositivo estético contemporâneo": muito embora estejam plenamente abertos a trabalhos que envolvam questões ideológicas complexas, os principais museus e galerias permanecem estrutural e institucionalmente impermeáveis aos efeitos do fazer artístico ${ }^{52}$.

É possível que essa resiliência seja um dos motivos que nos impede de reconhecer que o curador atua integralmente na mesma rede de criação do artista, desempenhando um papel de semelhante relevância em prol da expressão do trabalho de arte. A demarcação de território entre esses atores permanece rígida mesmo quando eles operam em franca colaboração ou assumem as tarefas um do outro.

Não obstante, quanto mais o fazer artístico esteja condicionado às suas formas de exibição, mais difícil será ignorar a preponderância das práticas curatoriais para a sua existência. Em certas ocasiões, o curador precisa inclusive assumir funções de produção e suporte, tornando-se efetivamente um co-realizador das obras ${ }^{53}$. 
Um caso em questão é o papel assumido por Harald Szeemann em GABRIEL MENOTTI seu inovador projeto Live in Your Head: When Attitudes Become Form: Works-Processes-Concepts-Situations-Information (1969). Essa foi a última exposição organizada por ele enquanto ainda era curador do Kunsthalle Bern (na Suíça), e viria a influenciar sobremaneira a sua prática (a partir de então) independente, divorciada das "funções programáticas de uma instituição" ${ }^{54}$.

When Attitudes Become Form buscava dar conta de uma série de formatos emergentes de produção artística, tais como a landart, a arte conceitual e a arte povera. De modo a lidar com as dificuldades em exibir esses trabalhos, Szeemann propôs "transformar a galeria em um estúdio, com os artistas viajando a Berna para produzir instalações e ações que se estendessem pelas ruas da cidade" ${ }^{55}$. Assim, o fazer artístico se encontrava plenamente sujeito ao seu contexto de apresentação, onde se dava em um prolongado diálogo com o suporte curatorial.

O professor de museologia Bruce Altshuler vê no projeto de Szeemann o início da "ascensão do curador como criador"- um fenômeno que, entretanto, não implicaria a usurpação do papel privilegiado do artista, mas sim uma reclassificação da prática expositiva como um "empreendimento crítico e potencialmente experimental" ${ }_{56}$.

Para Young Chul Lee, diretor do Centro de Arte Nam June Paik, da Coreia do Sul, tal empreendimento consistiria essencialmente em "inventar novos aparelhos que pudessem gerar diferentes leituras sobre os artistas e suas obras" ${ }^{\prime 57}$. De certa maneira, isso também se traduz numa ampliação das dimensões propositivas da curadoria, que, ao invés de simplesmente destacar o resultado de processos que (a princípio) lhe são avulsos, passaria a criar condições de trabalho para os artistas.

Estabelecendo plataformas de produção e consumo, o curador pode influir de modo acentuado tanto nas motivações quanto nos resultados finais do fazer artístico, sendo capaz de fomentar determinadas técnicas e programas de pensamento. Isso fica evidente, por exemplo, nas estratégias do galerista Seth Siegelaub para promover a arte conceitual.

Siegelaub desenvolveu uma série de abordagens curatoriais específicas para lidar com a imaterialidade desse tipo de produção. Entre as mais conhecidas está um tipo de contrato - o Artist's agreement, cuja primeira versão pública data de 1971 - que certificava a propriedade sobre obras impalpáveis, permitindo aos criadores negociá-las com terceiros ${ }^{58}$.

Já em termos de projeto expositivo, uma das invenções de Siegelaub

57. LEE, Young Chul. Curating in a Global Age. In: RAND, Steven, e KOURIS, Heather (eds.). Op. cit., p. 114.

58. ALBERRO, Alexander. Conceptual art and the politics of publicity. Cambridge: MIT, 2002, p. 164.

54. FOWLE, Kate. Who cares? Understanding the role of the curator today. In: RAND, Steven, e KOURIS, Heather (eds.). Op. cit., p. 30.

55. Ibidem.

56. Ibidem. 
foi The Xerox Book (1968), uma mostra em forma de catálogo da qual participaram artistas como Carl Andre, Joseph Kosuth e Sol LeWitt. Ao abra-

59. Ibidem, p. 133.

60. Ibidem, p. 3. çar a reprodutibilidade técnica possibilitada pela máquina de fotocópia, The Xerox Book representou uma "crítica vigorosa da obra de arte única e original que desprivilegia e despersonaliza o processo do fazer artístico" ${ }^{59}$.

Levando em conta as inovadoras práticas de distribuição e exibição divisadas por Siegelaub, Alexander Alberro o aponta como uma figura tão responsável pela criação da arte conceitual quanto os artistas expoentes desse movimento ${ }^{60}$. Para nós, também é interessante ressaltar como a sua atuação expandiu o alcance do território expositivo, ao mesmo tempo em que explicitou a agência das práticas curatoriais na materialização da obra de arte.

Ao operar de forma cada vez mais expressiva, chegando eventualmente a intervir nos processos de criação, os curadores parecem ocupar todas as posições relevantes do território das artes. Não é estranho que, logo, isso viesse a provocar o fenômeno contrário: uma proliferação de artistas organizando exposições.

Grosso modo, os artistas-curadores tinham por objetivo "retomar o poder do círculo de funcionários estatais e especialistas acadêmicos que parecia ter dominado a cena"61. O crítico Julian Stallabrass indica essa luta por autonomia como uma das características marcantes da produção banal e mercadológica que batizou de high art lite:

Figura 8 instalação original de Sixteen Miles of String (1942).

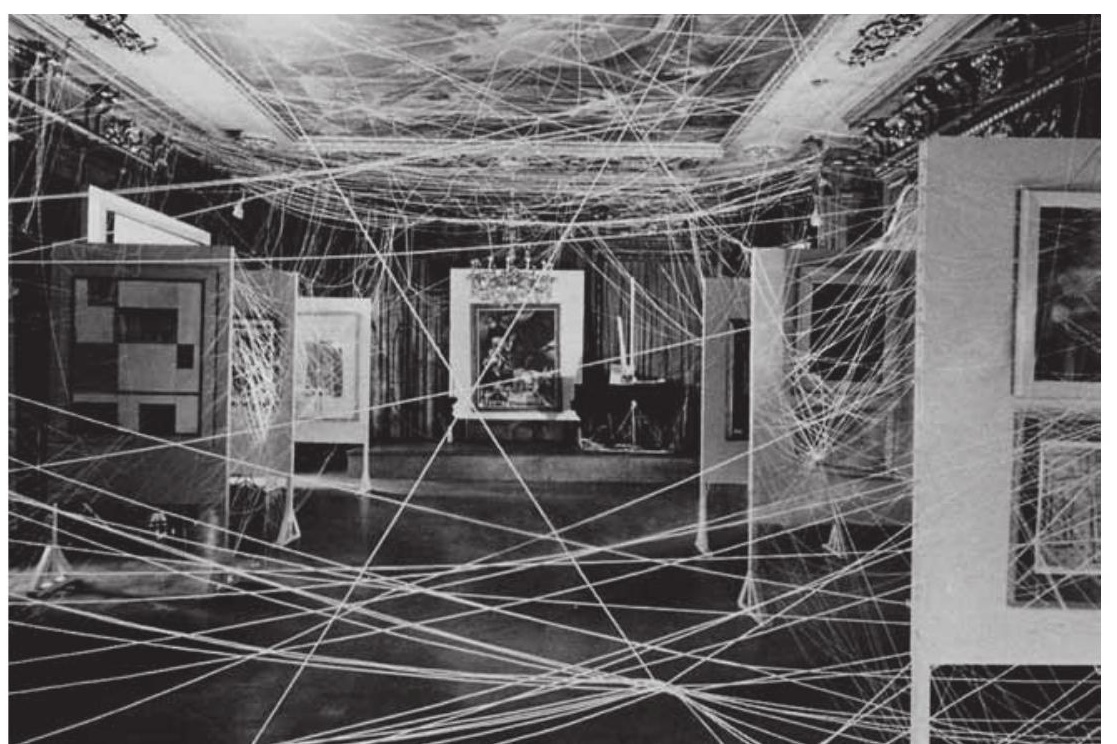


Os artistas organizavam suas próprias exposições em edifícios antes empregados como fábricas ou armazéns, contornando os aparelhos moribundos das galerias particulares e do setor público, que ainda não estavam preparados para o que eles tinham a dizer ${ }^{62}$.

Foi nesse esquema que, em 1988, o influente grupo dos Young British Artists montou a sua primeira exposição coletiva, Freeze. À época, eles não passavam de estudantes de graduação do Goldsmiths College, em Londres. O principal organizador do evento foi Damien Hirst, que cursava o segundo ano de Belas Artes. Hoje, Hirst é uma celebridade multimilionária, conhecido por empregar assistentes para produzir a maior parte das suas obras.

Nesse sentido, a atividade curatorial teria um óbvio apelo socioeconômico, possibilitando aos artistas abrir espaço no mercado para uma produção negligenciada pelo status quo acadêmico, estabelecer sua legitimidade junto ao público e assumir maior controle sobre os processos de criação.

Por outro lado, à luz das tendências promovidas pelo pós-modernismo e pela visualização de dados, a organização de exposições pode se mostrar como uma atividade genuinamente poética. O próprio Hirst é uma figura que não vê distinções de valor criativo entre "fazer arte" e "curar exibições", por considerar ambas como "formas de colagem"63.

Não obstante, a mera tolerância estética não nos ajuda a distinguir os complexos vínculos entre os processos de criação e as dinâmicas de poder institucional que são negociadas entre público, artistas e curadores. Pelo contrário, ao se consolidar como um gênero artístico, a exposição parece tornar esse entrelaçamento de forças ainda mais nebuloso.

Para dar corpo a essa última ressalva, tomemos como exemplo o singelo Learning to Love You More (2002-2009), um trabalho dos artistas Miranda July, Harrell Fletcher e Yuri Ono com dimensões claramente curatoriais.

Da mesma forma que outros projetos de exposição, Learning to Love You More partiu de uma chamada aberta de participação - ou melhor, de várias. Periodicamente, eram publicadas no site do trabalho propostas de atividade tais como "desenhe uma constelação a partir das sardas de alguém", "escreva a sua história de vida em menos de um dia" e "represente uma cena de um filme que fez alguém chorar”.

\section{GABRIEL MENOTTI}

Obras à mostra: articulações do trabalho de arte pelo desenho de exposição.

62. Ibidem, p. 49.

63. Ibidem, p. 30.

Figura 9

o Kunsthalle Bern durante When Attitudes Become Form (1969).

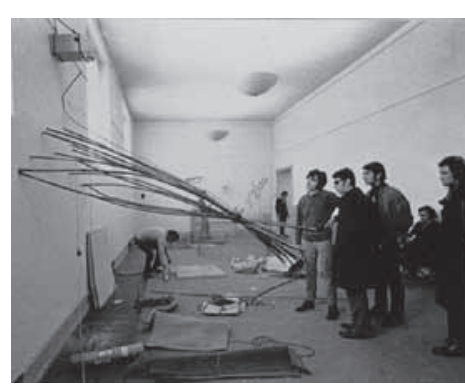


No total, setenta tarefas foram apresentadas. Qualquer pessoa poderia cumprir qualquer uma delas e enviar o resultado de volta aos artis-

64. JULY, Miranda; FLETCHER, Harrell; e ONO, Yuri. Hello. In: Learning to love you more, 2010. Disponível em: 〈http://goo.gl/ PKGm5>. Acesso em: março de 2012.

65. BOURRIAUD, Nicolas. Op. cit., p. 88.

66. LEE, Young Chul. Curating in a Global Age. In: RAND, Steven, e KOURIS, Heather (eds.).Op. cit., p. 114.

Figura 10 folha de rosto do The Xerox Book (1968).

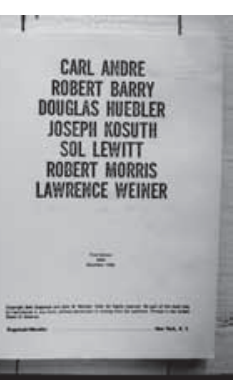
tas, que os publicavam na internet. Dessa forma, cada proposta dava origem a uma pequena galeria online, reunindo trabalhos nos mais diversos formatos: gravações de áudio, vídeos, textos, fotografias, desenhos, etc.

Até seu encerramento, em 2009, mais de oito mil pessoas tinham respondido às chamadas de Learning to Love You More ${ }^{64}$. Nesse meio tempo, o vasto acervo coletado pelos artistas se desdobrou em exposições em museus e galerias e ainda num livro. Finalmente, em 2010, o website do projeto foi adquirido pelo Museu de Arte Moderna de São Francisco (SFMOMA) para a sua coleção permanente.

Em sua aparente inocência, Learning to Love You More nos ensina uma lição sobre a perigosa fluidez das redes. Por um lado, é muito simples que os artistas assumam o papel de curadores, emprestando ao público o motivo, o espaço e a atenção necessários ao fazer artístico. Mas, da mesma forma, não existe nada que impeça a exposição de ser empacotada como uma obra sobre a qual os participantes não têm qualquer direito ou controle, e que estaria pronta para ser apropriada por uma instituição.

Logo, bem como pode renovar as tradições da arte, a interação com as novas mídias parece multiplicar ocasiões para que atores se transformem em elementos menores de uma assemblage; forças de mediação sejam convertidas em canais passivos; e o exercício de distinção e cuidado próprio das práticas curatoriais se revele como um modo de exploração do trabalho alheio.

\section{Por uma outra compreensão do desenho de exposições}

Como procurei demonstrar até aqui, o fazer artístico e as práticas curatoriais se desenvolveram pari passu, reorganizando um ao outro em reação tanto a fatores internos quanto externos ao mundo da arte. No circuito da arte contemporânea, essa interação entre artista e curador atingiu tal porosidade que seus papéis parecem efetivamente intercambiáveis.

Isso tem motivado novas formas de explicar o trabalho do curador, mais atentas às suas nuances operacionais. Nicolas Bourriaud, por exemplo, sugere uma analogia com a montagem, ou o "esquema de ação" cinematográfico $^{65}$. Young Chul Lee, por sua vez, vai encontrar a mínima unidade significativa de um projeto expositivo no simbiótico assemblage $e^{66}$. 
Entretanto, ainda falta um vocabulário que torne evidente que os GABRIEL MENOTTI supostos resultados do fazer artístico e das práticas curatoriais - respectivamente a "obra" e a "exposição"- sempre se encontraram inseridos na rede de criação um do outro de maneira fundamental. Em outras palavras, precisamos de uma abordagem mais minuciosa não para explicar o trabalho do curador, mas sim para entender a obra em exposição.

Proponho que uma tal perspectiva possa ser construída a partir da ideia de arranjo expositivo (exhibition design). Para tanto, podemos buscar referências na leitura de Bruno Latour sobre a prática e os princípios do design (2008).

Latour procura embutir nesse elemento uma complexidade semelhante a que teria dado ao "social". Nesse sentido, o design não seria uma dimensão cosmética das coisas, restrita à sua superfície aparente. Pelo contrário, se trataria de um procedimento que "pode ser aplicado a sistemas de produção cada vez mais vastos”, podendo implicar tudo aquilo que é "planejado, calculado, esquadrinhado, arrumado, embalado, empacotado, definido, projetado, consertado, escrito em código, eliminado e assim por diante" ${ }^{\prime 67}$.

A abrangência dessa interpretação seria justificada pela etimologia do termo, que viria literalmente de "desenho" (drawing) ou de "arranjar" (drawing together). O último sentido é preferido por este trabalho por enfatizar um caráter simultaneamente material e associativo que nos parece relevante à análise da exposição de arte.

Entre os atributos do design enumerados por Latour, nos interessa sobretudo uma certa humildade "que parece faltar à palavra 'construção”- e, poderíamos assumir, também à ideia de criação que até agora exploramos. Isso significa que no design, ao contrário de outras práticas, “não existe nada de fundacional”. Ressaltemos, em primeiro lugar, que um arranjo "nunca é um processo a partir do zero: arranjar é sempre rearranjar”. Além disso, ele não imprime nenhum valor ou sentido absoluto aos elementos nele reunidos, mas essencialmente "se dá a interpretações"

Com base nessas características, podemos pensar a obra à mostra 68. Ibidem, p. 4. como uma forma na qual uma rede de criação está arranjada para se apresentar ao público. Doravante, a exposição não seria nem a causa final nem um recipiente passivo do fazer artístico, mas um de seus pontos de articulação, cuja principal particularidade estaria na franca abertura a outros atores - como a instituição hospedeira, a audiência e os demais trabalhos. 
Esse deslocamento do nosso foco de atenção - do ciclo de produção e consumo da obra de arte para o seu arranjo conjunto - é capaz de inverter a compreensão habitual do fazer artístico, rejeitando a alegada autossuficiência do movimento criador em detrimento do modo como diversas redes se articulam publicamente. Isso nos induz a uma abordagem agnóstica, em que a situação de exposição se torna o seu próprio parâmetro de análise. Em outras palavras, somos levados a tomar a interação imediata entre os elementos presentes - quaisquer que eles sejam - como preponderante na constituição das obras de arte.

Dessa forma, a perspectiva do design nos permitiria traçar com maior precisão as dinâmicas de valor e sentido que se articulam indistintamente por meio de textos de parede, telas e pilastras, revelando o que está encoberto pela compartimentalização modernista: "que objetos sempre foram projetos; que matérias de fato sempre foram matérias de 69. Ibidem, p. 13. preocupação"69.

Artigo recebido em 13 de setembro de 2013 e aprovado em 22 de setembro de 2013.
Gabriel Menotti (gabriel.menottidgmail.com) é crítico e curador independente. Atualmente ocupa o cargo de Professor-Adjunto no Departamento de Comunicação Social da Universidade Federal do Espírito Santo (UFES). Já trabalhou como professor visitante na Middlesex University e no Goldsmiths College. Possui doutorado em Media and Communications pelo Goldsmiths College, Universidade de Londres (2011) e outro em Comunicação e Semiótica pela Pontifícia Universidade Católica de São Paulo (2012). Já apresentou trabalhos em eventos como ISEA, Bienal de São Paulo e Rencontres Internationales Paris/ Berlin/Madrid. Recentemente, publicou a monografia Através da sala escura (Intermeios, 2012), sobre salas de cinema e VJing. 